\title{
THE STUDENTS' PROBLEMS USING AEGISUB TO MAKE SUBTITLE OF ENGLISH-INDONESIAN MOVIE
}

\author{
ANDI ASMAWATI \\ UIN Alauddin Makassar \\ andi.asmawati@uin-alauddin.ac.id \\ DOI: https://doi.org/10.24252/elties.v2i1.12861

\begin{abstract}
This research was aimed at finding out the students' problems using Aegisub to make subtitles of English-Indonesian movies. Qualitative approach was used to describe the students' problems faced during translating English into Indonesian language (Bahasa). There were 16 students became the representative subjects. The data were collected through interview then it analyzed into 4 steps; they were coding, reducing, presenting, and concluding the data. The findings indicated that the students faced technical and linguistic problems. Technical problems were consisted of timing, typesetting, and codifying. Linguistic problems related to the diction choices, equivalence, and translation strategies that the students used to deliver the meaning of the subtitle to the viewers. Thus, the students' problems in making subtitle using Aegisub application were technical and linguistic problems.
\end{abstract}

Key words: Students' problems, Aegisub, subtitle.

\section{INTRODUCTION}

One of the subjects learned in English Education Department of UIN Alauddin Makassar is Theories and Practices of Translating. The materials taught to the students are the theories, kinds, and strategies of translating. These intend to prepare the students to be a good translator that possesses a proficiency in the translation field. They learn how to translate English into Indonesian or vise verse in many kinds of fields such as health, law, engineering, and economic. To explore the students' translation skill, they also learn Audio Visual Translation (AVT).

Audio Visual Translation is a branch of translation studies concerned with the transfer of multimodal and multimedia texts into another language and/or culture (Inghiller in Puspitorini, 2018). AVT is very different from printed media translation, such as books, texts or newspapers, and magazines. According to Goettlieb (2005), There are four types of channels that work simultaneously and together in an audio visual text, they are moving and non-moving images, writing which appears in the film and also the text (credit, toptitles and subtitles), sound which consists of sound effects and music (soundtrack), and speech utterances that has meaning. All kinds of utterances that are unclearly heard in the background of scenes are not included in this category. Learning translation through AVT makes the students capable to 


\section{Volume 2, Number 1, March 2020}

create subtitle for a movie by using an additional application like Aegisub and the movie can be acquired from any media, one of them is Youtube.

Youtube nowadays is one of the popular media which provides movie, tutorial, and many kinds of video that cannot be separated from subtitle. The subtitle is a text that written in the same language or different language from the source. For example, the video is spoken in English, the subtitle created can be in English or Indonesian text. The interesting part is there are still a large number of videos available on Youtube which remain blank with no subtitles either in the source or target language. These resourceful media are obviously becoming a wide area of practices for the students to create subtitles in the target language.

Subtitle is Audio Visual Translation so there are significant differences between subtitles and literary text translation in general such as novels. One of the distinguishing features is the limited number of letters, lines and accuracy between audio and text in one display frame to make subtitles unique by themselves. That is the reason why subtitles have their own strategies. Shuttleworth and Cowie in Widiani (2012) define subtitles as the process of providing synchronized captions for films and television dialogue. According to this definition, subtitling is a process of making translation texts that are synchronized with the original movie and television dialogue. This understanding focuses on the quality of the translation which must be synchronized in the existing dialogue on the audio-visual text. That is, good subtitles or audiovisual texts must be synchronous and in harmony with the dialogue or verbal signifier wich is contained in an audio-visual text.

In creating subtitle, the translators must understand the linguistic dimension in the process of translating subtitles. These dimensions include; summary and clarity, two-line subtitling, omissions, punctuation, structural differences, and swearwords. Sometimes a few words are expressed in the subtitling process. From these five linguistic dimensions of translation, the translator would easily make the subtitles according to their linguistic considerations. In addition, O'Connell (2007) divided subtitle into two kinds, they are interlingual subtitling and intralingual subtitling. Intralingual subtitle is the subtitling between two languages, it is a transfer from a Source Language (SL) to a Target Language (TL). Interlingual subtitle is the subtitling within the same language, it concerns the relationship between the same SL and TL. Alternatively, it is called intralinguistic since it works between the same languages (Gottlieb in Liu, 2014).

Aegisub is one of the applications used to produce subtitle. It is an open source software specifically used for creating and editing subtitles and karaoke text. Aegisub is widely used by fans of a movie to make their own (unofficial) subtitles called fansub. It was originally created 
as a tool for making typesetting especially in making anime captions. At the beginning of the project, there were other programs that supported Advanced Substation Alpha format, also known as SSA v4 + (.ass) but for various reasons and had many weaknesses, the program was finally dropped, the reason is it had no connection at all with Aegisubs, many unnecessary functions or too many bugs that make the program useless. Since then, Aegisub has grown to the fullest, highly adapted to become a subtitle editor which has many convenient features and tools to help the timing, typesetting, editing and translating text as well as a scripting environment called Automation.

One of the most important factors in subtitling is the timing or spotting. To our knowledge, measuring perfect timing in subtitling is an intricate work to do. However, using subtitling software such as Aegisub to measure perfect timing is deemed particularly appropriate (Sierra, 2014). Although Aegisub is free software that can be downloaded in http://www.aegisub.org/, it is equipped with a capability to do so. Thus, the writer as the lecturer feels that it is important to bring this software in translation classes.

The importance of introducing the students to Aegisub software is caused of the basics of technical features of subtitling such as timing, CPS (Character per second), and length of subtitles, are vital pieces that can only be processed solely by using this software. Moreover, CarollIvarsson in Vinczeová (2014) mentions other basic technical requirements, such as maximum two lines in one subtitle, number of characters should be limited to forty, maximum duration of a full two-line subtitle should be around 6 seconds, maximum duration of a full single-line subtitle should be around 3 seconds, CPS recommended to 12, and punctuation according to the standards of the recipient country should be used. These basic technical requirements can be analyzed by filling the subtitles produced into Aegisub and examining the video with subtitles, along with the intention of finding any inconsistency, whilst presenting technical information on the software toolbars. However, there are errors that become too redundant in the context of students or novice translators when making a subtitle. Vinczeová (2014) identifies that the errors range from too short pauses between subtitles, dialogues in one line, exceeding character number, and the longest and the shortest line.

Concerning to the use of Aegisub in creating subititle, the writer interested to find the students' problems of using that application. Making subtitles is not difficult if the students are used to do subtitling. Subtitles are familiar to the students of English Education Department of UIN Alauddin Makassar because they often watch foreign language movies that use Indonesian translations but it is different when they make the subtitles themselves. The students must know how to use the Aegisub application before they could produce their own subtitles. Therefore, 
the author investigated the difficulties that they encountered during making subtitles using Aegisub.

\section{METHOD}

\section{Research Subject}

The subject of this research were the Fourth semester students of English Education Department of UIN Alauddin Makassar. They were divided into 2 classes which cosisted of 80 students. The researcher chose the representative subjects using simple random sampling. There were 16 students selected as the representative subjects of this research.

\section{Research Design}

Qualitative approach was used to conduct this research. The data gained from the subject were described in narrative form. In other words, this research explained the students' problems that they faced in creating subtitle for a video using Aegisub.

\section{Data Source}

The Data were gained from the students through interview. The students selected as the representative of all of the subjects were the informants who gave the information about the problems that they encountered during the subtitling project.

\section{Research Procedure}

The researcher as the lecturer of Theories and Practices of Translating course gave the students subtitling project. They were divided into groups. The movies that they had to translate were one of the videos of Mondo World in Youtube which has duration between one hour to one hour and half. After the subtitling project done, the researcher selected the representative subjects. There were 16 students shared about their experiences using Aegisub and gave information about their problems using that application based on the researcher's questions.

\section{Data Analysis}

The data acquired from the subjects were collected and analyzed into 4 steps. The first step was coding. The researcher gave initial of the data. The second was reducing. In this step, the data were arranged and categorized to make summary from the main point of the information gained. The next was presenting the data in narrative form. The last was drawing conclusion. The researcher made conclusion about the students' problems using Aegisub. 


\section{FINDINGS AND DISCUSSION}

There were two problems that the students faced during subtitling project using Aegisub; they were technical and linguistic problems. Technical problems which came from spatial rules or parameter such as: number of lines, their position on screen, the principle of line-breaks, number of characters, and the feedback effects. Based on the statements from all of the interviewees, they felt difficult using Aegisub because they were not used to use it. The subtitling project was the first time they made a subtitle for a movie by themselves. The basic technical features of Aegisub such as timing and CPS drived them to learn more about its toolbars.

The students experienced scene bleeds at the several times. Scene bleed was something that happened if a timer did not clamp on a keyframe correctly. Making subtitle of a video was different with translating a textbook. The students should establish the exact time to cut the conversation or dialogue approppriated to the movie clips. According to the interviewee 3, the syncronization between the video and its subtitle took too much time, there were limited lines for the long dialogue that must be fit well. In addition, the interviewee 10 stated that it was difficult to make the subtitle line approppriated with the audio when the character talked too much and fast so that shortening the sentences should be flexible and clear to make the viewers enjoy when reading the subtitle of the video. This finding in line with the statement of Vinczeová (2014) who identified that the errors happened might be range from too short pauses between subtitles, dialogues in one line, exceeding character number, and the longest and the shortest line.

The other problem related to the technical problems was typesetting. The function of typesetting was to give special effects to the subtitle. Interviewee 7 stated that she got problem to change the font style and size of the subtitle. The choice of font style and size was important in subtitling to make the sentences readable for the viewers. The result of the students' subtitle showed the change font size after ten minutes of the 'Jungle Book' movie because the students did not consitent to set their font size and did not recheck their work. This problem related to the Palasworo's finding (2019) of his class observation that students' subtitle change into small size after 5 minutes because the students did not check and they made subtitle in separated place. In addition, interviewee 3 said that for beginner like him, it was very difficult to set the subtitle position and font style or size. The change of the font colour was also important to make the viewers interested. Several groups gave different colour effects to differentiate who were speaking of the video to interest the viewers. However, most of them were not consistent to change it so that the different colours of the video subtitle seemed useless. 


\section{Volume 2, Number 1, March 2020}

Iconifying was also including to the students' technical problem. There were a lot of icons in Aegisub menu bars that the students did not know its functions. Even the lecturer had explained and gave several tutorials, they confused to used them. Aegisub was the first application that the students used in Theories and Practices of Translating to make subtitle, Menu bars of that application were not familiar for them. Interviewee 15 explained that Aegisub was the new application for her. She confused the function of Aegisub toolbars, every icons looked similar. Actually, using Aegisub need more practices. When the students get familiar with the icons and toolbars, they could making subtitle efficient.

The second problem was the linguistics. According to Cintas (2014), linguistic problems were the space and time constraints inherent in the subtitling process usually enhance traditional translation challenges, such as grammar and word order, as well as problems related to cross-cultural. English and Bahasa have different structure and different culture. The diversity became the students' challenge to deliver meaning from English into Bahasa.

The videos that the students translate from Mondo World were spoken in English without English subtitle, it meant that the students translated the dialogue based on what they listened from the movie clips. Listening skill was very important in this process. However, not all of the students could get the dialogues of the movies so that they made improvisation or made blank space line to the dialogues that they could not be acquired.

Diction was one of the students' linguistic problems. They sometimes found unfamiliar words or many different terms, slangs, idioms, and cultural terms used in every movies. Moreover, there were many special terms and some similar words but they had different meanings according to the context of the movies. Based on the statement of interviewee 10, he said that it was hard to make subtitle because the meaning of the movies must be transferred in different language based on the context. Choosing the word or diction is important when someone wanted to translate the text or video. She/he had to search information about the terms used. Interviewee 16 stated that she had to be selective to find the dictions when translating the dialogues because the subtitle must be understandable for the children. The dictions should be considered carefully. The line must be readable and simple so that the children could get the meaning of the target language. In translation, a translator was required to get equivalent words so that the target language (subtitle) became accurate. Baker (1992) suggested several concepts of equivalence, namely word level equivalence; word equivalence; grammatical equivalence; text equivalence; and pragmatic equivalence.

Newmark (1988) stated that there were several types of translation strategies, namely: (1) transference; (2) naturalization; (3) cultural equivalence; (4) functional equivalence; (5) 
descriptive equivalence; (6) synonymy; (7) transposition; (8) modulation; (9) compensation; (10) componential analysis, (11) paraphrasing. In addition, Moentaha (2008) also suggested translation strategies, they were: (1) literal translation; (2) substitution; (3) free translation; (4) Replacement; including: substitution of word classes; substitution of sentence parts; lexical replacement; antonym; addition; reduction; compression; syntactic derivation; application; and implications. According to the interviewee 9, long conversation of the video clips made them shortened the subtitle. The clips and its subtitle must appear in the right time and the viewers must finish to read the subtitle a second before it disappeared. Several translation strategies like reduction were applied to overcome such the problems. In addition, interviewee 4 shared his experiences using linguistic application and compression to fit the subtitle and clip videos. He said that learning theories and strategies helped them in making subtitle.

Technical and linguistic problems that the students faced during accomplishing the subtitle task could be overcame by themselves by practicing more using Aegisub. The students' subtitle showed their translation skill, including how they chose appropriated dictions for the children. The font size and style also clear. However, there were several blank lines because they could not get the fast dialogues or unclearly spoken words.

\section{CONCLUSION}

Making subtitle using Aegisub differed from translating a textbook. There were several obstacles that the students faced during subtitling process, they were technical and linguistic problems. Technical problems were consisted of timing, typesetting, and iconifying. Linguistic problems related to the diction choices, equivalence, and translation strategies that the students used to deliver the meaning of the subtitle to the viewers. Thus, the students' problems in making subtitle using Aegisub application were technical and linguistic problems.

\section{REFERENCES}

Baker, M. (1992). Other Words: A Coursebook on Translation. London: Routledge.

Cintas, Jorge Diaz. (2014). Technological Strides in Subtitling. Journal from the Routledge Encyclopedia of Translation Technology Routledge, p. 632 - 643.

Gottlieb, H. (2005). Multidimensional Translation: Semantics Turned Semiotics. MuTra: Challenges of Multidimensional Translation: Conferense Proceedings, p. 1-28.

Liu, Dayan. (2014). The Classification of Subtitling. Journal of language Teaching and Research, 5 (5), p. 1103 - 1109.

Moentaha, MA. (2008). Bahasa dan Terjemahan. Jakarta: Kesaint. 
Newmark, P. (1988). A Textbook of Translation. London: Prentice Hall International.

O' Connell, Eithne. (2007). Choices of Constraints in Screen Translation (Unity in Diversity: Current Trends in Translation Studies). Beijing: Foreign Language Teaching and Research Press.

Palasworo, M. (2019). Students' Effort in Creating Subtitling Product of Sixth Semester English Language Education IAIN Surakarta. A thesis: State Islamic Institute of Surakarta.

Pupitorini, N.D. (2018). The Use of Aegisub to Translate English - Indonesian Videos in the Teaching and Learning of Subtitling on the Sixth Semester English Education Department of IAIN Surakarta in Academic Year of 2017/2018. A thesis: State Islamic Institute of Surakarta.

Sierra, J.J.M. (2014). The Use of Audiovisual Translation Software in Second Language Teaching. Journal of Foreign Language Teaching and Translation Studies, 3(1), p. 7484.

Vinczeová, B. (2014). Using Fansubbing as an Interdisciplinary Tool for Subtitle Teaching in the Slovak Context. European Journal of Social and Human Sciences, 10(2), p. 89-97.

Widiani, Agustin. (2012). Analisis Teknik, Metode dan Ideologi Penerjemahan Subtitle Film'Leapyear' Versi Non-Komersial dan Versi VCD Resmi dan Dampaknya pada Kualitas Terjemahan. A thesis. Surakarta: Sebelas Maret University. 